DRISTIKON, VOL. 11(1), 127-144, 2021, RMC, MMC, DHARAN

\title{
Dyscalculia in Learning Mathematics: Underpinning Concerns for Delivering Contents
}

\author{
Rajendra Kunwar \\ Associate Professor \\ Department of Mathematics Education, Mahendra Ratna Multiple Campus, Ilam, TU, Nepal \\ rajendrailam@gmail.com
}

DOI: https://doi.org/10.3126/dristikon.v11i1.39154

\begin{abstract}
Dyscalculia is a term that affects the ability to acquire arithmetical skills. It is one of the important areas of a specific learning disorder in mathematics covering the areas particularly, number sense, memorization of arithmetic facts, accurate and fluent calculation, and accurate math reasoning. It is estimated that about 3-6 percent of the population is facing problems associated with dyscalculia. This paper explores the theoretical consideration of dyscalculia in learning mathematics and outlines the ways of employing effective pedagogy to address dyscalculic students. The study is based on theoretical and descriptive methods. It focuses on the theoretical concern about learning mathematics, dyscalculia, its meaning and concept, types, causes, common difficult areas and impacts on mathematics learning. It also draws out the way of effectively delivering content and provides support for the dyscalculic learner. This article concludes that dyscalculic learners are facing various difficulties due to their weak number sense, low basic mathematics fluency, reasoning and accurate arithmetic calculation. Thus it is essential to provide specialized instruction as well as extra support to uplifts and retain the skills and performance of the dyscalculic learner in mathematics. Otherwise, the arithmetic inability can lead the learner to more difficult circumstances that may be beyond the classroom learning context.
\end{abstract}

Keywords: content delivery, dyscalculia, learning deficit, learning mathematics, student support

\section{Introduction}

Mathematics is considered to be a difficult subject due to its abstract nature. The difficulty of learning mathematics is a global issue. Mathematics is considered a very important subject in school-level education due to its close relationship to daily human activity. As a result, it is taught as a fundamental and compulsory subject in schools all over the world and positioned as an important subject in the school curriculum. Accordingly, it has always been given special 
attention in school education globally (Kunwar, 2021). Even though the expected outcomes in mathematics could not be achieved to date and the students' negative attitude towards learning mathematics also could not be reduced (Kunwar \& Sharma, 2020). For many years, it was believed that the numerical cognition of the children could be developed according to the child development and the learners can be taught effectively using Piaget's child developmental stages (Piaget, 1952). The Piaget's philosophy was focus on the child understanding about space, time and causality of number and quantity, and classes and relations of invariance and change (Baccaglini-Frank \& Di Martino, 2020).

In the present situation, however, the researchers are focusing increasingly on the causes of mathematical learning difficulties as procedural as well as neurobiological foundations of the learner (Sharma, 2020). Mathematics is conceived as a product of human activities in the process of adapting to the external environment (Baccaglini-Frank \& Di Martino, 2020). It helps to perform fast and accurate arithmetical calculations in adolescence and adulthood (Tolar et al., 2009). Researchers have generally agreed that the deficit in working memory, brain-related condition, genetic cause, environment, and brain difference is considered dyscalculia (Hornigold, 2015). The causes of such deficits and inability of the learner particularly affect arithmetic fact retrieval, basic processing of numbers, reasoning, working memory, visual-spatial processing significantly. As stated by Khing (2016), such deficits affect the learners' mathematical learning capability particularly computation and reasoning. In the long run, such problems related to the learning deficit of the learner gradually tend to create frustration to learn and solve mathematical problems regarding computation and application (Chinn, 2015). Thus, it is a deeper-rooted mathematics learning problem that is spotted from the beginning of primary school age. Dyscalculia is a lifelong problem (Hornigold, 2015), however, it can be eased with well-targeted support and intervention.

\section{Research Problems}

Dyscalculia is a kind of learning problem in mathematics. It is also denoted as a specific type of mathematics learning disability. According to Hornigold (2015), approximately $25 \%$ of students in a class are supposed to struggle with mathematics difficulties at different points in their studies. As stated in the report of the National Assessment of Student Achievement (NASA) [2019], a huge mass of students is at the underperforming level, especially in mathematics. Thus, dyscalculia may be one of the causes of low achievement in mathematics. A recent study shows that $6.8 \%$ of the school-level students in Nepal were found dyscalculic (Kunwar \& Sharma, 2020). Similarly, they also found that $54.13 \%$ of teachers were found to have an average level of knowledge specifically, $67.33 \%, 60 \%, 59.33 \%$ and $52 \%$ of the teacher were found to have an average level of knowledge about the meaning and concept of 
dyscalculia, characteristics of dyscalculia, effects of dyscalculia and intervention strategies of dyscalculia respectively. This scenario shows that knowledge exploration concerning the different aspects of dyscalculia is necessary to minimize the problem related to dyscalculia. Kunwar and Sharma (2020) also stressed the managerial practices and instructional priorities in schools to be addressed the problem related to learning disability especially dyscalculia in the context of Nepal. Thus, the impact of dyscalculia in learning mathematics has been observed as a crucial problem among the students as well as the teacher. The study mainly focuses on the problem related to mathematics learning difficulty for dyscalculic students. Thus, it contributes to how the dyscalculic learners can be treated better to enhance their mathematics learning.

\section{Research Objectives}

The objectives of this paper are:

i) To explore the theoretical understanding of dyscalculia in learning mathematics.

ii) To outline the ways of implementing effective pedagogy to address the dyscalculic students.

\section{Materials and Methods}

The study is based on theoretical and descriptive-analytic methods. It is used to disclose the concept and meaning of dyscalculia, type, causes, areas of common difficulties, and impacts. Similarly, the method is also revealing the components of learning mathematics, effective ways of content delivery and student support for dyscalculic students. This method uses descriptive analysis and synthesizes the relevant facts and reasons to explore the information regarding dyscalculia in a synthesized form. In this process, mainly secondary sources of data or literature are used to explore the ideas and knowledge about the theoretical aspects of dyscalculia and utilizing effective pedagogy to deal with the dyscalculic students. In this course, various research literature such as reports, publications, periodicals, books, journals and newspapers were reviewed to collect the information for the study. Most of this literature was used from the digital open sources or databases such as journal achieves library databases, and different digital learning platforms.

\section{Results and Discussion}

\section{Components of Effective Mathematics Instruction}

Mathematics learning can be defined as the acquisition of new knowledge and skills in the different areas of mathematics. It is a very important subject that encompasses numbers, measurement, probability, and algorithms (Nagavalli, 2015). It cannot be separated from the particular cognitive processes in operation whenever we apply our minds to a mathematical task (Sharma, 2020). It is sometimes expressed as a difficult subject that is inaccessible, boring, 
particularly for cool and engaged people and girls (Boaler, 2016). Mathematics is considered as an integral part of our daily life. It is used in daily activities such as shopping, playing, cooking, arranging something, etc. As described by Ziegler \& Loos (2017), mathematics was developed from counting, calculation, measurement and the systematic study of the shapes and motions of physical objects. From the beginning, mathematics was considered as the science of quantity, or numbers. Effective mathematics instruction and learning mathematics require three equally important hierarchical components that can help to transform the mathematical concepts, ideas and knowledge effectively. These components of mathematics instruction are stated briefly as:

\section{Language component}

The language component is the first component in learning mathematics. It is the first and a key component used in instruction that describes mathematical terms, notations, concepts, ideas and procedures to develop mathematical knowledge and understanding. The main role of this component is conceptualizing and communicating the mathematical information to the learner. Mathematics learning starts from counting physical objects and gradually goes forward with concepts of quantity, size and comparisons. The language component continues to help students move from concrete mathematical skills based on physical objects to a more symbolic mathematics ability focused on numerals (Kolkman, Kroesbergen \& Leseman, 2013). Thus, it is the most useful component in instruction for the teacher to address the mathematical concepts, problems and procedures to the learner more clearly.

\section{Conceptual component}

The conceptual component of learning mathematics refers to a conceptual understanding of the actual meaning and intends to increase literacy in mathematics rather than stepwise teaching to find the solutions. It helps the learner to transfer the knowledge in a new situation and context. It focuses on explaining why the processes rather than performing how the process and influences the later perceptual part-whole judgments (In Cohen \& In Lefebvre, 2017). Conceptual learning begins in early childhood by using different effective methods, modern tools and techniques. In brief, the conceptual component can add considerably to our cognitive capacities and processes, in particular those connected with learning, concept formation, reasoning, and language understanding (Gil, 2017). Thus, it is necessary to learn mathematics with understanding for building new knowledge and transfer it into new context both by the teacher and learner.

\section{Procedural component}

Procedural component or fluency refers to the ability to apply procedures efficiently, accurately, and flexibly; to transfer procedures to different problems and contexts; to build or modify procedures from other procedures; and to recognize when one strategy or procedure is 
more appropriate to apply than another (NCTM, 2014). Procedural fluency is not only the memorizing facts or procedures but is the foundation of conceptual understanding. The procedural component can be used effectively when the conceptual proficiency is high or the procedural fluency depends on the conceptual understanding (Graven \& Debbie Stott, 2012).

\section{Concept of Dyscalculia}

Dyscalculia is a specific type of learning disability. It affects the learner's ability to retain mathematics skills related to calculating numbers, not with every branch of mathematics (Kunwar \& Sharma, 2020). It is an umbrella term used to represent diverse conditions that cause specific difficulties with mathematics such as mathematical disability, developmental dyscalculia, numerical learning disability, and number fact disorder among other terms (Emerson \& Babtie, 2010). Therefore, dyscalculia is an inherited condition that affects the capability of the learner to obtain mathematical skills.

The term 'dyscalculia' has both Greek and Latin origins. The Greek prefix 'dys' means 'badly', while 'calculia', from the Latin 'calculare', means to count (Khing, 2016). It was first defined as the difficulty in mathematics due to the impairment to particular parts of the brain involved in mathematical cognition, but without a general difficulty in cognitive function by the Czechoslovakian researcher Kosc in 1974 (Soares \& Patel, 2015). Dyscalculia is also known as 'being bad at mathematics', 'difficulty with numbers', or 'number blindness'. Hornigold (2015) stressed dyscalculia as a more deeply-rooted problem than just being bad at mathematics or only difficulty with numbers.

Dyscalculia affects the learners' ability to understand the logical steps needed for solving a mathematical problem, memorize number-based facts and performing daily numerical tasks. It refers to the inability or disorder in basic numerical processes in mathematics (Kunwar et al., 2021). Grant (2017) states that the specific learning deficits in mathematics have memorization of arithmetic facts, number sense, accurate or fluent calculation and mathematical reasoning. Among them, number sense can be classified as dyscalculia and the core deficit of dyscalculia is the lack of numerosity or the inability to understand the concept of more than/less than (Grant, 2017). Therefore, dyscalculia is considered as the specific difficulty in understanding number and number relationships.

Dyscalculia is also considered a neurological disorder regarding learning abilities in mathematics. It is a brain-based disorder as indicated by genetic, neurobiological, and epidemiologic evidence (Shalev, 2004). It has a strong correlation between neurobiology and dyscalculia (Kucian \& Von Aster, 2015; Soares \& Patel, 2018). As stated by Hornigold (2015) around $6 \%$ of the children have dyscalculia and are being equally affected regarding both girls and boys. The common range of dyscalculia lies between 3-6\% of school-age children (Kucian 
$\&$ von Aster (2015). However, Sharma (2020), claimed that the occurrence of dyscalculia is about 6 to 8 percent of the school-age population. Dyscalculic children consist of two types of problems- mathematical computation and reasoning (Khing, 2016). Mathematical computation affects the learner while calculating mathematical problems. Similarly, mathematical reasoning affects the learner in the case of analyzing and way of thinking (Kunwar et al., 2021). Such mathematical problems usually begin at the elementary level and generally continue throughout their lifespan (Hornigold, 2015).

\section{Types of Dyscalculia}

Dyscalculia can be categorized into different types based on their different dimensions. In the field of mathematical learning disability, different researchers have explored their ideas to categorize the major types of dyscalculia concerning the different dimensions of acquiring mathematical ability. In this context, Kosc (1974), the researcher, who proposes dyscalculia into six uniform categories particularly focusing on the characteristics of knowledge deficits are as follows:

\section{Verbal dyscalculia}

Verbal dyscalculia denotes the disturbing ability to designate verbally mathematical terms and relations, such as naming amounts and numbers of things, digits, numbers, operational symbols and mathematical performances (Kosc, 1974). In verbal dyscalculia, children can read or write numbers, but they feel difficult to recognize the verbal structure.

\section{Prognostic dyscalculia}

Prognostic dyscalculia indicates the difficulty to manipulate mathematical real or pictured objects. Such mathematical manipulations consist of enumerations and comparisons. Children with this type of dyscalculia can understand mathematical concepts however they have trouble in listening, comparing, and manipulating mathematical equations.

\section{Lexical dyscalculia}

Lexical dyscalculia represents a reading disability of mathematical symbols (digits, numbers, operational signs, and written mathematical operations). In this sort of disability, children may have trouble in reading and understanding mathematical symbols, numbers, mathematical expressions, and/or equations.

\section{Graphical dyscalculia}

Graphical dyscalculia is a disability in manipulating mathematical symbols in writing. Children can understand; however, they feel trouble while writing or using the correct corresponding symbols. They may also be unable to copy them if written. 


\section{Ideognostical dyscalculia}

Ideognostical is a type of dyscalculia that is difficult to carry out mental calculations and understanding mathematical ideas and relations. Children having Ideognostical dyscalculia feel difficulty with completing mental operations and remembering mathematical concepts after learning them.

\section{Operational dyscalculia}

Operational dyscalculia is the inability to carry out mathematical operations or calculations due to the typical occurrence by an interchange of operations, e.g., doing addition instead of multiplication; subtraction instead of division; or substitution of more complicated operations by simpler ones.

Karagiannakis and Cooreman (2014) have categorized dyscalculia into four ways based on different aspects of mathematical ability or areas of mathematics that affect the learner. The brief accounts of the types are as follows:

\section{Core number}

Core number dyscalculia consists of the difficulties related to basic number sense or the ability to use and understand the number and our number system, estimating, assessing numerical differences in quantity, understanding and the use of mathematical symbols, place value and placing numbers on a number line.

\section{Reasoning}

Reasoning dyscalculia encompasses the difficulties related to understanding mathematical concepts and relationships, generalizing and transferring mathematical information, understanding complex procedures including problem-solving and decision making.

\section{Memory}

Memory dyscalculia includes the difficulties associated with remembering and retrieving numerical facts, understanding and recalling mathematical terminology, word problems, performing accurate mental calculations, remembering and carrying out procedures, rules and formulae, performing problem-solving steps.

\section{Visual-spatial}

Visual-spatial dyscalculia consists of the difficulties concerning recognizing and understanding mathematical symbols, interpreting visual representations of mathematical objects, representing numbers on a number line, visualizing geometrical figures, interpreting graphs and tables.

\section{Causes of dyscalculia}


The causes of dyscalculia can be classified from a different perspective. There are diverse views about the causes of dyscalculia. Nevertheless, researchers are generally agreed about dyscalculia as a brain-based condition. Arguably, dyscalculia can be categorized within the cognitive, behavioral and biological aspects and contextualize in teaching and learning mathematics. It can also be considered as the fundamental cause of dyscalculia or the factors affecting dyscalculic learners. The fundamental cause of dyscalculia is presented in three categories in Figure 1.

\section{Figure 1}

Fundamental Causes of Dyscalculia

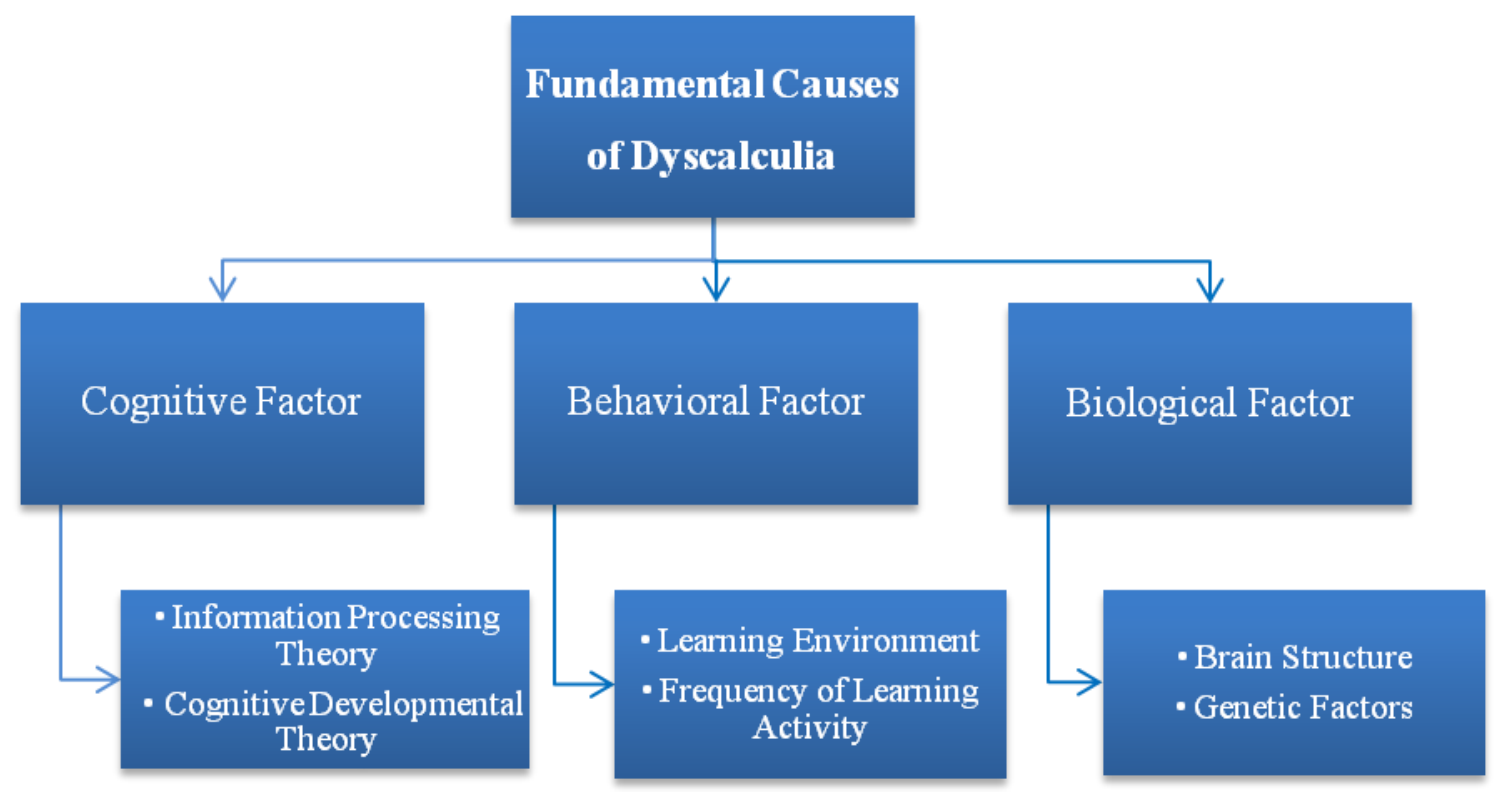

In Figure 1, the causes of the dyscalculia in the cognitive factor, the possession of number concepts and the ability to acquire arithmetical skills and understanding, some huddles during the development stages of Piaget's child development theory can be the cause of dyscalculia. In the same way, the information processing theories can also be the cause to accommodate the number concept and difficulty with numbers (Dehaene \& Cohen, 1997). In behavioral factors, learning environment, various aspects related to effective teaching and learning such as teaching methods, materials, motivation, classroom environment, sociocultural factors, stress, anxiety, etc. can also be the causes to acquire the number concept and arithmetic skills (Murphy et al., 2006). Frequent learning activities or drills and practice can 
also help to attain the learning problems related to numbers. The biological factor comprises the development of brain structure and genetic characteristics. The development of brain structure may depend upon prematurity and low weight birth. In the same way, dyscalculia can be transformed from the heredity factor too (Shalev, 2004).

\section{Key Indicators of Dyscalculia}

Dyscalculia has some common key indicators that dyscalculic children often struggle with number and number concepts that can lead to a diverse range of difficulties related to numbers in mathematics. Jacobson (2020) stated that dyscalculic children have difficulties related to recognizing and remembering numbers, counting, associate number symbol with the number value, identifying patterns and placing things in the right order. With the reference of Butterworth \& Yeo (2004); Hornigold (2015); Jacobson (2020), some common areas of difficulty in mathematics for dyscalculic children can be discussed briefly in the following subheadings.

\section{Counting backward, sequencing and recognizing patterns}

It is related to counting stepwise or with sequence backward numbers. It is also related to recognizing the number pattern such as odd, even, multiples of numbers, etc. In such conditions, dyscalculic children feel trouble with recognizing patterns and sequencing numbers.

\section{Number calculations and direction/orientation}

It is related to the operation of numbers and number lines. Dyscalculic children find it difficult to choose the correct numerical operation such as addition, subtraction, etc. and apply it correctly. They also find it difficult to sort out direction, spatial orientation and confusion over left, right, high, low and depth.

\section{Time, estimation and assessing the numerical quantity}

The time telling on an analog clock also creates a problem for the learner. Understanding place value, problem-related to estimating quantities from the given numbers or numeric values, mathematical concepts, rules and formulae. Identify the number numerically larger or smaller.

\section{Mental mathematics, fractions and money}

It is related to difficulty in remembering procedures in mathematics to recognize quantities without counting, recalling basic math facts, linking numbers and symbols and problemsolving. Poor visual and spatial orientation also makes the children difficult in fraction diagrams. In the same way, they find it difficult in the sense of money and estimating quantities.

\section{Impact of Dyscalculia}


The impact of dyscalculia in learning mathematics has a great deal. It impacts children from the early age of schooling onwards. It affects learning mathematics as well as in daily life activities due to the inability of basic arithmetic concepts like poor number sense and reasoning. Dyscalculia can impact various aspects of children's mathematics learning in everyday activities. It develops a negative attitude and avoids the tasks like judging distances, direction, depth and distinguish between left and right; larger and smaller numbers (Zerafa, 2019). Likewise, it de-motivates and makes it difficult to learn mathematics because of poor understanding of mathematical concepts, rules, formulae, and proper sequencing. Similarly, unable the children to concentrate a long time continuously on mentally concentrated tasks and also make challenges in daily life due to their poor number sense and other mathematics skills (Hornigold, 2015).

Similarly, it reduces the self-efficacy of the learner about learning mathematics due to the constant difficulty on the problem related to amounts, time, distance, speed, counting, mental mathematics, and remembering numbers. Develop low self-esteem and always hesitate to argue or express the views related to mental arithmetic and numeric calculation such as addition, subtraction, multiplication and division that in turn impact on student's performance (Dowker, 2008). In the same way, it makes unhappy and unenthusiastic constantly in mathematical activity due to the lack of common mathematics abilities like remembering number facts, times tables, counting backward, telling time, calculations relating to money, decimals, fractions, and percentages (Hornigold, 2015).

\section{Effective Modes of Content Delivery}

The effective mode of content delivery is the process of delivering teaching activities and subject matter to the learner through either the physical or virtual medium. There are a large number of ways to deliver the content. Effective mode of content delivery depends upon how the learner has internalized or understood the subject matter. The effective mode of content delivery for dyscalculic learners also depends upon the learners' interests, background, and capability. However, the multi-sensory techniques incorporating best suited modern tools and techniques with the need and interest of the learner can make the content delivery more effective. Some major modes of effective content delivery are stated as:

\section{Make it real}

The teaching concerning the key areas of mathematics that find difficult for the dyscalculic learner should make real. While teaching number and concept, use varied concrete materials available around the locality and also use readymade or prepared materials such as Cuisenaire rods, Base ten-block, Numicon, Abacus, Ten-frames, etc. so that multi-sensory approach can be 
used to make real learning that can help the dyscalculic learner to develop number concepts, place value and mathematical reasoning.

\section{Make learning fun}

The content delivery mode 'Make learning fun' is a way in which the subject matter can be delivered effectively by making the teaching and learning environment fun. Poor concepts and understanding of mathematics produce fears and unpleasant consequences (Kunwar, 2020). As a result, use of Dominoes, playing games with Dice, Ten-frames, etc. can make learning fun and also familiarize with the face of Dice, dot patterns of Dominoes and counting and number relations in Ten-frames, etc. that can help the learner to be more familiar with dot patterns, counting and number relations.

\section{Provide sufficient time}

Enough time for the learner should be provided while teaching mathematics. The use of concrete materials in teaching helps to develop a clear concept about mathematical terms and understand the relationship between numbers and number systems through manipulating the materials. It further helps to develop mental arithmetic skills effectively. The learner should be provided sufficient time to manipulate the real object, a variety of concrete and semi-concrete materials. The use of such materials helps the learner to explore the facts, patterns, concepts, meaning, and understanding of the subject matter of mathematics and also broadening their reasoning power.

\section{Visualize more}

Visualization is the effective process of sensation to an object. It is used frequently in classroom instruction. While teaching in the classroom, visualize the mathematics subject matter by using concrete materials if possible; otherwise, visualize by drawing diagrams to model the subject matter. The visualization process in teaching mathematics helps the learner to grasp the subject matter successfully and also develop self-efficacy towards the subject matter.

\section{Make learning multi-sensory}

Multi-sensory learning helps the learner to internalize the content efficiently, concentrate more actively in the learning process. This process makes learning more effective, practical as well as permanent. When the learners are involved actively in learning, they learn more sincerely and effectively. Thus the multi-sensory mode of instruction can be the most efficient way of delivering content for the dyscalculic learner.

\section{Use modern technology}


The use of technology not only assists in delivering the contents but also helps to make education assessable to the learner through online mode. It helps to provide online resources to every learner easily and makes the learning collaborative. The use of technology makes learning more effective and interactive too. It can be employed to speed up, enhance and intensify basic skills in reading, writing and arithmetic (Kunwar, 2020). It enables the student to learn better by increasing their engagement in educational activities. It is used in the learning process which makes learning faster, easier and fun. It provides better opportunities for special needs children to play, enjoy and learn mathematics as fun. Thus, the use of technology helps the dyscalculic learner to learn mathematics in a fun and in an interactive way.

\section{Use collaborative learning}

Collaboration is to work jointly or in a group. So in this learning, a group of people learns and works together to solve the common problem or the assigned task. In this approach, the students are given certain clues and encourage them collaboratively solving the problem. In this type of learning, the learners are actively engaged to learn and develop their understanding. It helps to motivate the learner and inspires them to engage and enjoy learning mathematics. Collaborative learning particularly helps the learner to share the skills and ideas to complete the task.

\section{Rapport building}

Rapport building is a concern to the close relationship between students and the teacher that helps to develop a positive learning environment. It also helps the students to motivate in learning mathematics and also develop mutual trust, friendship and affinity with someone. It makes a close relationship with the teachers and makes it easy to ask questions to their teacher frequently whenever they feel difficulty in learning. These two ways of communication certainly help the students reduce their learning difficulties. Rapport building particularly helps to established understanding, attention, and expectations between the students and the teacher so that the students can engage in a high degree of attention in the learning process.

\section{Adaptive teaching}

Every child learns differently and their learning process is affected by various factors such as motivation, prior knowledge and their ability to learn. So the adaptive teaching approach focuses to meet the individual need of the learner. In this approach, the role of the teacher is to monitor each learner and adjust them for instruction according to their needs. This approach utilizes a variety of teaching methods and materials to the different groups of learners according to their level, need and interest to achieve success (Borich, 2011). This approach is aimed at achieving a common instructional goal with the students whose individual differences, 
prior achievement, aptitude and learning styles differ (Ikwumelu et al., 2015). Thus it focuses on individualized instruction to achieve the common instructional goal with the learners.

\section{Teach less but regular}

In this mode of instruction, the subject matter is divided into small separable parts so that each part can be taught effectively in a small amount of time. Also, the small part of the content can be taught regularly using different effective techniques. So, the learners can also feel more comfortable learning the small part in a fewer time. When the students are taught a long lesson, it takes more time and the learners also feel bored and tired. Such instructional mode can be utilized effectively in the lower classes and also be used to teach the weak students. It can be employed most effectively to the dyscalculic learner who does not prefer to carry on the lengthy instructional strategy.

\section{Student Support}

The meaning of students' support covers a diverse area. In this study, student support focuses on day-to-day individual needs with an emphasis on academic success and helps to promote their ability to process and understand information regarding mathematics for struggling children with dyscalculia. It can also assist them in conceptualizing and performing mathematical difficulties. It is essential to work with dyscalculic children by teachers and parents both at home and school to develop a positive attitude towards learning mathematics and provide additional support for learning mathematics effectively. Generally, student support helps dyscalculic children to motivate in learning and overcome their particular mathematics learning difficulty. Parental and teacher support for the dyscalculic students are stated as:

\section{Parental Support}

Mostly, the children spend somewhat more time at home rather than school and they feel closer to their parents than others at the age of primary stage. So every parent can help their children effectively in several ways who struggle with dyscalculia. They can provide support to their children in various aspects of learning mathematics. Parents can motivate their children towards learning mathematics by telling stories of success or myths. The child's positive attitude towards learning mathematics can be increased by providing plenty of time to the child for talking, playing and other fun activities that the child likes to do.

The depressed, anxious, or discourage children can be supported by providing regular counseling and creating a helpful environment to understand each other's feelings and needs. The children can be supported by listening and addressing their interests and feeling as far as possible. Similarly, proper guidance to their homework and other learning problems and timely management of the learning materials such as bags, books, stationery and other materials can 
also support the children. Timetable management is very important for children at the beginning stage of schooling. So, they should be supported to manage their time such as for playing, homework, reading and writing, etc. Praise and encouragement for the learner or the acknowledgment of their success and hard work also assist or support for learning mathematics.

\section{Teacher Support}

The dyscalculic children need additional support and instruction at school and home due to poor working memory. The teacher can support the dyscalculic learner at school in the real classroom environment that is also the best place for children to deal with some of their difficulties. Teacher support and encouragement help them to self-motivate and continuing their learning. The teacher support helps the students to reduce their mathematics anxiety that they often become anxious and makes them unable to concentrate on learning mathematics. The teacher can support the students by providing sufficient supportive tools for teaching and learning mathematics that can help the child to navigate the difficult problems. The teacher can support the students by focusing on mathematical games, puzzles and activities to erase particular misconceptions of the students such as mathematics is a difficult subject and help to revisit important topics regularly and develop interest and enjoyment in learning mathematics.

The teacher can develop a positive mindset for the learner by providing encouragement, praise, and support to their every successful activity in the classroom. Revision of the lesson frequently and the use of real-life examples make the students easier to understand and make them more familiar with mathematical problems. Similarly, the use of technology in teaching and the use of different applications, games and puzzles related to mathematics make teaching fun and interactive too. The teacher can support their students by implementing a stepby-step teaching approach for the weak students and can provide continuous and extra support to the dyscalculic students. They also can provide maximum time for practicing the difficult areas of mathematics to their students. In the same way, they can reduce the overloaded homework for the young child and can reduce homework-related tensions for both students and parents.

One more thing should always be cautious that learning disabilities affect both the child and families. So the students struggling with dyscalculia may affect themselves from their parents. Parental attitudes and parenting styles affect the children and their attitude toward learning. So the parents should be timely informed about their child's condition and progress and their responsibilities towards their child.

\section{Conclusion}

Dyscalculia is a much deeper-rooted problem related to numbers and reasoning not just being bad at mathematics. It is a specific learning disorder that influences the arithmetical abilities of 
the learner. They have also difficulties in numerical calculations in their daily activity. Thus the arithmetical deficits not only impact their achievements but also on other related fields beyond the class. It is often first spotted from the primary grades. The dyscalculic student should face more difficulty in the areas of mathematics such as estimation, time, assessing numerical quantities, money, sequencing and recognizing the patterns, counting backward, and direction, etc. Thus, there are certain areas of difficulty in learning mathematics for the dyscalculic learner where they cannot attempt in time due to the low basic mathematics fluency and reasoning however, that can be alleviated with well-targeted support and intervention. Thus, it is a specific difficulty of learning mathematics that affects the ability of the learner in some particular areas of mathematics. Teaching in such difficult areas of mathematics, the dyscalculic students should be provided with specialized instructions and dedicated time. Similarly, they should be cared and well treated at school by providing extra classes. In the same way, the parents should also provide sufficient time at their home to address their problems. As a result, the dyscalculic students can boost up through employing effective instructional strategies.

\section{References}

Baccaglini-Frank A., \& Di Martino, P. (2020). Mathematical learning difficulties and dyscalculia. In Lerman S. (eds) Encyclopedia of Mathematics Education. Springer, Cham. https://doi.org/10.1007/978-3-030-15789-0_100018

Boaler, J. (2016). Mathematical mindsets: Unleashing students' potential through creative math, inspiring messages, and innovative teaching. Jossey-Bass.

Borich, G. D. (2011). Effective Teaching Methods. Pearson Education, Inc.

Butterworth, B., \& Yeo, D. (2004). Dyscalculia guidance: Helping pupils with specific learning difficulties in Maths. NferNelson.

Chinn, S. J. (2015). The Routledge international handbook of dyscalculia and mathematical learning difficulties. Routledge. https://doi.org/10.4324/9781315740713

Dehaene, S., \& Cohen, L. (1997). Cerebral pathways for calculation: double dissociation between rote verbal and quantitative knowledge of arithmetic. Cortex, 33, 219-250.

Dowker, A. (2008). Mathematical difficulties: psychology and intervention. Elsevier.

Emerson, J., \& Babtie, P. (2010). The dyscalculia assessment foreword by Brian Butterworth. Continuum International Publishing Group. 
Gil, D. (2017). Isolating-Monocategorial-Associational Language. Handbook of Categorization in Cognitive Science, 471-510. https://doi.org/10.1016/b978-0-08101107-2.00020-8

Grant, D. (2017). That's the way I think: Dyslexia, dyspraxia, ADHD and dyscalculia explained (3rd ed.). Routledge.

Graven, M. \& Debbie Stott, D. (2012). Conceptualizing procedural fluency as a spectrum of proficiency. Proceedings of the 20th Annual Conference of the Southern African Association for Research in Mathematics, Science and Technology Education.

Hornigold, J. (2015). Dyscalculia: Pocketbook. Teachers' Pocketbooks.

Ikwumelu, S. N., Oyibe, O. A. \& Oketa, E. C. (2015). Adaptive teaching: An invaluable pedagogic practice in social studies education. Journal of Education and Practice, 6 (33), 140-144.

In Cohen, H., \& In Lefebvre, C. (2017). Handbook of categorization in cognitive science. Elsevier.

Jacobson, R. (2020). How to spot dyscalculia. Child Mind Institute. https://childmind.org/article/how-to-spot-dyscalculia/

Karagiannakis, G. \& Cooreman, A. (2014). Focused MLD intervention based on the classification of MLD subtypes. In Chinn, S.J. (Eds.). The Routledge International Handbook of Dyscalculia and Mathematical Learning Difficulties, Routledge.

Khing, B. (2016). Dyscalculia: Its types, symptoms, causal factors and remedial programs. Learning Community, 7(3), 217-229. https://doi.org/10.5958/2231458X.2016.00022.1217-229.

Kolkman, M. E., Kroesbergen, E. H., \& Leseman, P. P. (2013). Early numerical development and the role of non-symbolic and symbolic skills. Learning and Instruction, 25, 95103.

Kosc, L. (1974). Developmental dyscalculia. Journal of Learning Disabilities, 7(3), 46-59. https://doi.org/ 10.1177/002221947400700309

Kucian, K., \& Von Aster, M. (2015). Developmental dyscalculia. European Journal of Pediatrics, 174(1), 1-13. https://doi.org/10.1007/s00431-014-2455-7

Kunwar, R. (2020). Mathematics phobia: Causes, symptoms and ways to overcome. International Journal of Creative Research Thoughts, 8(8), 818-822. 
Kunwar, R., \& Sharma, L. (2020). Exploring teachers' knowledge and students' status about dyscalculia at basic level students in Nepal. EURASIA Journal of Mathematics, Science and Technology Education, 16(12), em1906. https://doi.org/10.29333/ejmste/8940

Kunwar, R., Shrestha, B. K., \& Sharma, L. (2021). Are teachers aware of mathematics learning disabilities? Reflections from basic level schoolteachers of Nepal. European Journal of Educational Research, 10(1), 367-380. https://doi.org/10.12973/eu-jer.10.1.367

Murphy, K., Darmawan, H., Schultz, A., Fidalgo, da Silva, E., \& Reha-Krantz, L. J. (2006). A method to select for mutator DNA polymerase deltas in saccharomyces cerevisiae. Genome, 49(4), 403-410.

Nagavalli, T. (2015). A study of dyscalculic primary school children in Salem district and evaluation of the applicability of innovative strategies as remedial measures. Department of Educational Research and Policy Perspectives. Sri Sarada College of Education.

NASA. (2019). Report on the National Assessment of Student Achievement (Grade 5: Mathematics and Nepali), Sanothimi: Education Review Office.

National Council of Teachers of Mathematics. (2014). Procedural fluency in mathematics. A position of the national council of teachers of mathematics. Reston VA: Author.

Piaget, J. (1952). The origins of intelligence in children. (M. Cook, Trans.). http://doi.org/10.1037/11494-000

Shalev, R. S. (2004). Developmental dyscalculia. Journal of Child Neurology, 19, 765-771. http://www.pedneur.com/article/S0887-8994(00)00258-7/pdf

Shalev, R.S. et al. (2001) Developmental dyscalculia is a familial learning disability. Journal of Learning Disabilities, 34(1), 59-65.

Sharma, M. (2020). Mathematics for all. Mathematics education workshop series at Framingham State University. Mathematics Education Workshop Series.

Soares, N., \& Patel, D. (2015). Dyscalculia. International Journal of Child and Adolescent Health, 8(1), 15-26. Retrieved from http://libproxy.uwyo.edu/login/?url=https://searchproquest-

Soares, N., Evans, T., \& Patel, D. R. (2018). Specific learning disability in mathematics: A comprehensive review. Translational Pediatrics, 7(1), 48-62. https://doi.org/10.21037/tp.2017.08.03 
Tolar, T. D., Lederberg, A. R., \& Fletcher, J. M. (2009). A structural model of algebra achievement: computational fluency and spatial visualization as mediators of the effect of working memory on algebra achievement. Educational Psychology, 29(2), 239-266.

Zerafa, E.(2019). Helping children with mathematics learning difficulties: An intervention program carried out with children with mathematics learning difficulties only and children with both mathematics learning difficulties and reading difficulties. [Unpublished doctoral dissertation]. Faculty of Education, University of Malta.

Ziegler, G.M., \& Loos, A. (2017). What is mathematics? And why we should ask, where one should experience and learn that and how to teach it. In Kaiser G. (eds), Proceedings of the 13th International Congress on Mathematical Education. ICME-13 Monographs. Springer, Cham. https://doi.org/10.1007/978-3-319-62597-3_5 